\title{
Article
}

\section{The triterpene echinocystic acid and its 3-0-glucoside derivative are revealed as potent and selective glucocorticoid receptor agonists}

Georgatza, Demetra, Gorgogietas, Vyron A., Kylindri, Paraskevi, Charalambous, Maria Ch., Papadopoulou, Kalliope K., Hayes, Joseph and Psarra, Anna-Maria G.

Available at http://clok.uclan.ac.uk/16510/

Georgatza, Demetra, Gorgogietas, Vyron A., Kylindri, Paraskevi, Charalambous, Maria Ch., Papadopoulou, Kalliope K., Hayes, Joseph ORCID: 0000-0002-7745-9616 and Psarra, Anna-Maria G. (2016) The triterpene echinocystic acid and its 3-O-glucoside derivative are revealed as potent and selective glucocorticoid receptor agonists. The International Journal of Biochemistry \& Cell Biology, 79 . pp. 277-287. ISSN 13572725

It is advisable to refer to the publisher's version if you intend to cite from the work. http://dx.doi.org/10.1016/j.biocel.2016.08.028

For more information about UCLan's research in this area go to http://www.uclan.ac.uk/researchgroups/ and search for <name of research Group>.

For information about Research generally at UCLan please go to http://www.uclan.ac.uk/research/

All outputs in CLoK are protected by Intellectual Property Rights law, including Copyright law. Copyright, IPR and Moral Rights for the works on this site are retained by the individual authors and/or other copyright owners. Terms and conditions for use of this material are defined in the policies page. 


\title{
The triterpene echinocystic acid and its 3-O-glucoside
}

\author{
derivative are revealed as potent and selective
}

\section{glucocorticoid receptor agonists}

\section{Demetra Georgatza $^{\mathrm{a} 1}$, Vyron A. Gorgogietas ${ }^{\mathrm{a} 1}$, Paraskevi Kylindri ${ }^{\mathrm{a}}$, Maria Ch.}

Charalambous $^{\mathrm{a}}$, Kalliope Papadopoulou ${ }^{\mathrm{a}}$, Joseph M. Hayes ${ }^{\mathrm{b}}$, Anna-Maria G. Psarra ${ }^{\mathrm{a}}$

aDepartment of Biochemistry and Biotechnology, University of Thessaly, Larissa,

Greece

${ }^{\mathrm{b}}$ School of Physical Sciences \& Computing, Division of Chemistry, University of Central Lancashire, Preston PR1 2HE

*Corresponding Author: Dr. Anna-Maria G. Psarra; Department of Biochemistry and Biotechnology, University of Thessaly, 26 Ploutonos and Aiolou, 41221, Larissa, Greece; Tel: +30-2410-565221; Fax: +30-2410-565290; email:ampsarra@ bio.uth.gr 
${ }^{1}$ Equal contributors. 


\begin{abstract}
Abbreviations
GCs, glucocorticoids; GR, glucocorticoid Receptor; SEGRA, selective glucocorticoid receptor agonist; EA, echinocystic acid; EA-3G, echinocystic acid 3-O-glucoside, PEPCK, phosphoenolpyruvate carboxykinase; NF- $\kappa \mathrm{B}$, nuclear factor kappa beta; TNF $\alpha$, tumour necrosis factor alpha; CMX, MitoTracker Red CMXRos; DEX, dexamethasone; DAC, Deacylcortivazol; GREs, glucocorticoid responsive elements; LBD, ligand binding domain; HPA, hypothalamic-pituitary-adrenal; RLU, relative luciferase units; $\mathrm{CRH}$, corticotropin-releasing hormone; iNOS, inducible nitric oxide synthase; IFD, induced-fit docking; ChIP, chromatin immunoprecipitation
\end{abstract}


Abstract

Glucocorticoids are steroid hormones widely used to control many inflammatory conditions. These effects are primarily attributed to glucocorticoid receptor transrepressional activities but with concomitant receptor transactivation associated with considerable side effects. Accordingly, there is an immediate need for selective glucocorticoid receptor agonists able to dissociate transactivation from transrepression. Triterpenoids have structural similarities with glucocorticoids and exhibit anti-inflammatory and apoptotic activities via mechanisms that are not welldefined. In this study, we examined whether echinocystic acid and its 3-O-glucoside derivative act, at least in part, through the regulation of glucocorticoid receptor and whether they can constitute selective receptor activators. We showed that echinocystic acid and its glucoside induced glucocorticoid receptor nuclear translocation by $75 \%$ and $55 \%$. They suppressed the nuclear factor-kappa beta transcriptional activity by $20 \%$ and $70 \%$, respectively, whereas they have no glucocorticoid receptor transactivation capability and stimulatory effect on the expression of the phosphoenolopyruvate carboxykinase target gene in HeLa cells. Interestingly, their suppressive effect is diminished in glucocorticoid receptor low level COS-7 cells, verifying the receptor involvement in this process. Induced fit docking calculations predicted favorable binding in the ligand binding domain and structural characteristics which can be considered consistent with the experimental observations. Further, glucocorticoids exert apoptotic activities; we have demonstrated here that the echinocystic acids in combination with the synthetic glucocorticoid, dexamethasone, induce apoptosis. Taken together, our results indicate that echinocystic acids are potent glucocorticoid receptor regulators with selective transrepressional activities 
(dissociated from transactivation), highlighting the potential of echinocystic acid derivatives as more promising treatments for inflammatory conditions. 


\section{Introduction}

Glucocorticoids (GCs) are essential steroid hormones for human life. They regulate a series of important processes by binding to their cognate receptors, the glucocorticoid receptors, (GR) (Evans, 1988). Activated cytoplasmic GR can directly bind nuclear DNA and transactivate or transrepress specific genes, critical for growth, development, metabolism, immune response and apoptosis. Additionally, it can interact with other transcription factors to affect gene expression indirectly (Kassel and Herrlich, 2007). The localization of glucococorticoid receptor in mitochondria and its implication in the regulation of mitochondrial functions has also been documented (Psarra et al., 2005; Sionov et al., 2006; Psarra and Sekeris, 2009a, 2011; Psarra et al., 2009b, Du et al., 2009). In addition, binding of GCs to membrane GR can also trigger GCs' non-genomic actions (Borski, 2000). Thus, GCs, through their cognate receptor (GR) promote actions, such as induction of gluconeogenesis, breakdown of proteins into amino acids, reduction in glucose utilization, and stimulation of the mobilization of fatty acids (Rose and Herzig, 2013). More importantly, GCs are well known for their anti-inflammatory actions which are mediated by a) the negatively glucocorticoid response element mediating DNAdependent GR transrepression of inflammatory genes or b) the DNA-independent interactions of GR with other transcriptions factors such as NF- $\kappa$ B and Stat3 (Refojo et al., 2001). Due to their immunosuppressive and anti-inflammatory actions, GCs are the most effective therapy in the treatment of acute and chronic inflammatory, as well as autoimmune diseases (Baschant et al., 2013; Oakley and Cidlowski, 2013). GCs are also considered as a major component of the treatment of many oncology disorders due to their proapoptotic properties (Schmidt et al., 2004). 
However, the supra-physiological doses and chronic use of exogenous GCs can give rise to undesirable side effects. Among these are diabetes, osteoporosis, muscle wasting, growth retardation in children, disturbed water balance, fat redistribution, mood disorders and suppression of the Hypothalamus Pituitary Adrenal (HPA) axis resulting in disturbed production and regulation of endogenous cortisol. The most predominant side effects of GCs are of catabolic nature. These catabolic actions are due to the primarily function of GCs to increase serum glucose by inducing gluconeogenesis, which in part relies on protein degradation and lipolysis. Although it is assumed that the anti-inflammatory effects of GCs are mainly due to GR transrepressional mechanisms, the GR transactivation is accountable for the greater part of GCs side effects, such as diabetes and muscle wasting. However, side effects such as HPA axis suppression arise from GR transrepressional activities, whereas others such as osteoporosis are mediated by both transactivation and transrepression (Sundahl et al., 2015). Accordingly, there is a significant need for potent selective steroidal or non-steroidal glucocorticoid receptor agonist (SEGRAs) or modulators (SEGRMs) as effective as classic GCs, but with a reduced side effect profile (Kleiman and Tuckermann, 2007; De Bosscher et al., 2010; Vandevyver et al., 2013). These compounds can bind to the same or to different GCs binding sites in Cterminal of the ligand binding domain (LBD) of GR and may cause different GR conformational changes (Sundahl et al., 2015).

Echinocystic acids (EAs) are triterpenoids that exert anti-inflammatory and apoptotic activities. The molecular mechanisms of ECs actions are not yet welldefined. It is proposed that EAs exert anti-inflammatory actions through interfering with NF-kB pathway (Joh et al., 2012) and inhibition of proinflammatory cytokine expression (Gene et al., 1996; Ryu et al., 2013; Joh et al., 2012, 2014, Ma et al., 
2016). Apoptotic activities of certain EAs derivatives are attributed to activation of JNK- and p38 kinase- mediated mitochondrial pathways and to regulation of protein expression of proapoptotic and antiapoptotic molecules (Tong et al., 2004a, 2004b; Lee et al., 2005, Cho et al., 2016). Recently, the anti-depression, osteoprotective and anti-diabetic activities of EAs have also been proposed (Kumar et al., 2012; Deng et al., 2015; Li et al., 2016; Yang et al., 2016).

In this study, considering the structural and functional similarities of echinocystic acid (EA) and its 3-O-glucoside derivative (EA-3G) with GCs (Fig. 1), we investigated whether EA and EA-3G mediate their actions, at least in part, through the regulation of GR signalling. To this end, three parameters, namely the GR nuclear translocation, ligand induced dissociation of GR transactivation and trans-repression, and induction of mitochondrial dependent apoptosis in the presence of EAs were examined by employing immunohistochemistry, Western blot analysis, luciferase reporter gene and chromatin immunoprecipitation (ChIP) assays, in GR positive human cervical carcinoma HeLa cell line and/or in GR low level COS-7 cells. Using induced-fit docking (IFD) analysis, the predicted binding of EA and EA-3G in the LBD was examined and compared to the well-studied dexamethasone (DEX), a synthetic glucocorticoid.

\section{Materials and Methods}

\subsection{Chemicals}

Dulbecco's modified Eagle medium (DMEM), fetal bovine serum (FBS), MitoTracker Red CMXRos (CMX), and lipofectamin 2000 were obtained from 
Invitrogen. Molecular weight protein markers were from Fermentas, complete protease inhibitors cocktail were purchased from Roche (Mannheim, Germany). All other chemicals including dexamethasone (DEX) were purchased from Sigma-Aldrich (St. Louis, MO). EAs were purchased from Extrasynthese, France.

\subsection{Antibodies}

The GR-H300 affinity purified polyclonal GR antibody, which recognizes an epitope corresponding to amino acids $121-420$ of human GR, and was commercially provided by Santa Cruz Biotechnology, was used. Monoclonal antibodies against $\beta$ actin (Sigma Aldrich) and caspase 9 (Cell Signalling), and rabbit polyclonal antibodies against phosphoenolpyruvate carboxykinase (PEPCK) (Santa Cruz), caspase 3 (Abcam), Bcl-2 (Cell Signalling) and the p65 subunit of NF-kB (Santa Cruz) were also applied.

\subsection{Cell Culture}

Human HeLa and HEK293 cells were maintained in DMEM, supplemented with $10 \%$ FBS, $2 \mathrm{mM}$ glutamine, and penicillin/streptomycin. Cells were grown at $37^{\circ} \mathrm{C}$ in a humidified atmosphere with $5 \% \mathrm{CO}_{2 .} 48-72 \mathrm{hrs}$ before treatment, cells were cultured in phenol red free-DMEM medium supplemented with $10 \%$ charcoal inactivated FBS, $2 \mathrm{mM}$ glutamine, and penicillin/streptomycin.

\subsection{Immunostaining - fluorescence microscopy}


Cells grown on coverslips, in DMEM without phenol red supplemented with $10 \%$ charcoal inactivated serum for $48 \mathrm{hrs}$, were transiently transfected with a pEGFPC2GR construct (Psarra and Sekeris, 2011). The next day, cells were incubated for $2 \mathrm{hrs}$ with various concentrations of EAs range from $0.1 \mu \mathrm{M}$ to $20 \mu \mathrm{M}$ or $0.1 \mu \mathrm{M}$ and $1 \mu \mathrm{M}$ DEX, washed with PBS, fixed for $10 \mathrm{~min}$ at $-20^{\circ} \mathrm{C}$ in methanol, transferred to acetone $\left(-20^{\circ} \mathrm{C}\right)$ for $2 \mathrm{~min}$, briefly air-dried and mounted in polyvinyl alcohol-based anti-fading medium. Additionally, cells grown on coverslips, in DMEM without phenol red supplemented with $10 \%$ charcoal inactivated serum, were incubated for $1 \mathrm{hr}$ at $37{ }^{\circ} \mathrm{C}$ with $200 \mathrm{nM}$ MitoTracker Red CMXRos (CMX), in the presence or absence of $10 \mu \mathrm{M}$ EAs and or $1 \mu \mathrm{M}$ dexamethasone, washed with PBS, and fixed in methanol-acetone $\left(-20^{\circ} \mathrm{C}\right)$. After three washings (5 min each), immunocytochemistry was proceeded using primary GR antibodies (final dilution of 1:50), appropriate secondary antibodies conjugated with Alexa fluor 488, provided by Invitrogen, diluted 1/500, and $1 \mu \mathrm{M}$ Hoechst 33342 (Sigma-Aldrich). Specimens were mounted in polyvinyl alcohol-based anti-fading medium (Psarra and Sekeris, 2011). Cell specimens were observed with a Leica 2000 DM microscope. Images were obtained with the optiMOS (Qimaging) camera.

\subsection{NF- $\kappa B$ and GR activity}

HeLa cells growing on 24-well plates were co-transfected with a NF- $\kappa \mathrm{B}$ Luciferase (NF-kB-Luc), or an MMTV-GRE (Glucocorticoid response elements of the murine mammary tumour virus DNA) promoter-driven luciferase construct (GRLuc reporter gene construct) and a $\beta$-galactosidase reporter construct, in the presence or absence of a pEGFPC2 or a pEGFPC2GR construct (Psarra and Sekeris, 2011) 
using Lipofectamin 2000 according to manufactures instructions. Cells were treated either with TNF $\alpha$ (tumour necrosis factor $\alpha ; 10 \mathrm{ng} / \mathrm{ml}$ ) for $6 \mathrm{hrs}$ and/or with $1 \mu \mathrm{M}$ DEX in the presence or absence of $10 \mu \mathrm{M}$ EAs. Subsequently, cells were lysed in report lysis buffer (Promega), following the manufacturer's protocol, and assayed for the expression of luciferase and $\beta$-galactosidase activity (Psarra et al., 2009). The light emission was measured using a chemiluminometer (LB 9508, Berthold) and adjusted to the $\beta$ - galactosidase activity of the sample. Transfection efficiency was expressed as relative luciferase units (RLU).

\subsection{Electrophoresis and Western Blotting}

Cells grown on 6 well plate, for $48 \mathrm{hrs}$ in phenol red free medium supplemented with charcoal inactivated fetal bovine serum, were incubated for additional 48-72 hrs with $10 \mu \mathrm{M}$ EAs and/or $1 \mu \mathrm{M}$ DEX and with $10 \mu \mathrm{M}$ EAs or 1 $\mu \mathrm{M}$ DEX in combination with $10 \mu \mathrm{M}$ RU 486, a synthetic GR antagonist. Cells were washed in PBSX1, lysed in buffer A $(20 \mathrm{mM}$ Tris pH:7.5, $250 \mathrm{mM} \mathrm{NaCl}, 0,5 \%$ Triton, 3 mM EDTA) supplemented with cocktail preotease inhibitors (Rosche). After Bradford protein determination (Bradford, 1976), cell extracts were electrophoresed in discontinuous SDS-PAGE and Western blotted with specific antibodies against GR, $\beta$-actin, PEPCK, Bcl-2, caspase 3 and caspase 9 as previously described (Psarra et al., 2005). $\beta$-actin expression levels were evaluated for the normalization of the PEPCK, GR, Bcl-2, procaspases -3 and -9 expression levels. Enhanced chemiluminescence was used for the detection of the protein bands. 


\subsection{ChIP assay}

Chromatin immunoprecipitation was performed as previously described (Psarra et al., 2011, see also supplementary data). The GR specific monoclonal antibody (2F8), produced and kindly provided by Dr. M. Alexis (Hellenic Research Foundation), or normal mouse $\operatorname{IgG}$ as control were used for the immunoprecipitation. The bound DNA fragments were eluted purified, concentrated, amplified and quantified by real-time PCR. Binding of GR to the glucocorticoid hormone response elements in the promoter region of the PEPCK gene was checked using the following primers: Forward: ACAGAGCAGACAATCAATACAGT; Reverse: TGAATGCTGGGAGACTTCGA. Recovery of DNA was calculated as percentage of input material of the immunoprecipitation.

\subsection{Statistical analysis}

All results are expressed as mean \pm SD $(n=3-5)$. Data were analysed by independent t-test or by analysis of variance followed by Tukeys's post-hoc test using SPSS software. Differences were considered significant at a two tailed P value $<0.05$.

\subsection{Induced-fit docking calculations}

The ligands (EA, EA-3G, DEX and DAC) were prepared for calculations using LigPrep 3.6 (Schrödinger, 2016) with the OPLS3 forcefield (Harder et al., 2016), while the LBD of GR protein was prepared for docking using its solved crystallographic complex (PDB code: 3BQD) with deacylcortivazol (DAC), (Fig. 1). 
The initial setup of the GR structure for calculations was performed using Schrodinger's "Protein Preparation Wizard" (Schrödinger, 2016). Schrödinger IFD calculations (Sherman et al., 2006) of EA, EA-3G, DAC and DEX to the ligand binding pocket of GR were then performed (Schrödinger, 2016). Detailed information for the analysis and validation of the protocol employed is provided as supplementary data.

\section{Results}

3.1. Echinocystic acid and its 3-O glucoside derivative induce GR nuclear translocation.

Structural similarities of EAs with the natural cortisol and the synthetic corticosteroid, dexamethasone (Fig 1), prompted us to examine whether EAs are capable in inducing GR nuclear translocation. Various concentrations of EAs, range from $0.1 \mu \mathrm{M}$ to $20 \mu \mathrm{M}$ and DEX at concentrations of $0.1 \mu \mathrm{M}$ and $1 \mu \mathrm{M}$ was checked for their efficacy to induce nuclear translocation of a GFP-GR fused protein transiently expressed in HeLa and HEK293 cells. As shown in supplementary Fig. S1, DEX at concentration of $0.1 \mu \mathrm{M}$ and $1 \mu \mathrm{M}$ activate approximately $100 \%$ of nuclear localization of the glucocorticoid receptor, as widely demonstrated in the literature. In the presence of EA and EA-3G, more than $30 \%$ and $10 \%$ increase in GR nuclear translocation was observed at concentrations of $2 \mu \mathrm{M}$ and $5 \mu \mathrm{M}$, respectively. EAs at concentrations of $10 \mu \mathrm{M}$, showed further increase in GR nuclear translocation by 5\%$20 \%$, reaching almost a plateau. Since, both compounds were active, at concentration of $10 \mu \mathrm{M}$, the effect of $10 \mu \mathrm{M}$ EAs on native GR nuclear translocation in HeLa cells, 
was checked in comparison to the effect of $1 \mu \mathrm{M}$ of DEX. As it is shown in Figure 2, upon DEX induction, GR is thoroughly translocated from the cytosol to the nucleus, as was expected. In the presence of EAs, cytosolic GR staining is reduced, whereas GR nuclear staining is strengthen compared to control cells, verifying the steroid activity of EAs as regard activation of GR nuclear translocation. Figure 1, also shows that EA is more effective ( $35 \%$ increase) than EA-3G (15\% increase) in the activation of GR nuclear translocation, compared to control cells. This observation indicates that both compounds can bind to GR, but possibly EA binding favors GR nuclear translocation.

\subsection{EAs-induced GR nuclear translocation does not induce GR} transcriptional transactivation

Luciferase reporter gene assays, using a MMTV-GRE promoter driven luciferase construct, revealed that the EAs-induced GR nuclear translocation was not accompanied by GR transcriptional activation (Fig. 3). As was expected, incubation of HeLa cells with $1 \mu \mathrm{M}$ DEX caused approximately 5 fold increase in GR transcriptional activity. On the contrary, in the presence of $10 \mu \mathrm{M}$ EAs, GR transcriptional activity was not only increased but slightly reduced compared to controls (Fig. 3A). Assessment of the effect of EAs on the expression of PEPCK, the well-known gluconeogenic GR target gene, revealed a moderate reduction in the protein levels of PEPCK in HeLa cells, treated with $10 \mu \mathrm{M}$ EAs, for 48-72 hrs (Fig. 3B). This reduction is more pronounced in the presence of DEX in combination with the EAs compounds (Fig. 3B). Similar results were also observed as regards the effect of DEX and EAs on GR protein levels. This observation was also verified in HepG2 
cells (Data not shown). Normalization of PEPCK protein levels against fluctuations of actin and GR protein levels, revealed the expected DEX induced increase in PEPCK protein levels (by approximately $100 \%$ ), in HeLa cells (Fig. 3C). Combination of EA or EA-3G with DEX showed an antagonistic effect of EAs on the DEX-induced increase in PEPCK protein levels, resulting in reduction in PEPCK levels by approximately 100\% (EA) and 60\% (EA-3G), (Fig. 3B, 3C). In addition, ChIP analysis revealed no statistically significant binding of GR to the promoter region of PEPCK, in the presence of EA, whereas EA-3G induced moderate binding, approximately $60 \%$ lower than that observed by DEX (Fig. 3D). RU 486, the DEX antagonist, did not affect the EAs effect on PEPCK expression (Fig 3B, 3C).

\subsection{EAs interfere with $G R$ signalling in inhibition of $N F-\kappa B$ activity}

In order to explore the effect of EAs on NF- $\kappa \mathrm{B}$ activity, HeLa cells were

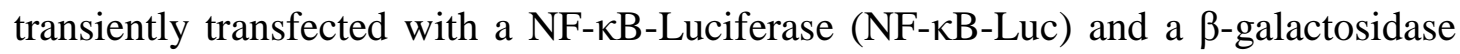
construct. Subsequently, cells were triggered with TNF $\alpha(10 \mathrm{ng} / \mathrm{ml})$ or equal volume of PBS in the presence or absence of EAs (Fig. 4). Measurements of luciferase activity revealed that EAs suppressed the transcriptional activity of NF- $\kappa \mathrm{B}$ in the TNF $\alpha$ sensitized cells. This was not evident in the control, non-sensitized cells. More specifically, EA caused approximately $25 \%$ inhibition of the TNF $\alpha$ induced NF- $\kappa$ B transcriptional activation, whereas the EA-3G showed a higher anti-inflammatory activity, exhibiting approximately $70 \%$ inhibition of the NF- $\kappa \mathrm{B}$ activity (Fig. 4A). Subsequently, in order to examine whether EAs possible interfere with GR actions, the effect of EAs on NF- $\mathrm{BB}$ transcriptional activity was evaluated in the absence or presence of DEX in HeLa cells, transiently overexpressing the GFP or the GFP-GR 
fused proteins. As shown in Figure 4B, increased levels of GR caused approximately $50 \%$ reduction in the TNF $\alpha$-induced NF- $\kappa \mathrm{B}$ activity compared to conditions with endogenous GR level. As was expected, DEX suppressed the TNF $\alpha$ action on the NF- $\kappa \mathrm{B}$ activity in both controls (GFP overexpressing) and GFP-GR overexpressing cells, by approximately 40\%. Interestingly, EA-3G showed comparable to DEX activity, in both type (GFP and GFPGR overexpressing) of the TNF $\alpha$ sensitized cells, whereas EA exerted weaker inhibitory effect on the NF- $\mathrm{BB}$ activity, compared to DEX (20\% inhibition). Both compounds, when administered in combination with DEX, showed more than $100 \%$ increase in their inhibitory activity compared to conditions administered alone. The GR-mediated anti-inflammatory activity of EAs

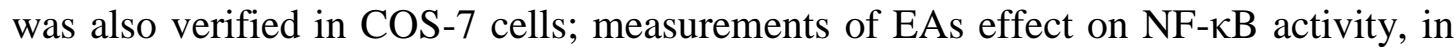
the almost GR-negative COS-7 cells, showed no statistically significant effect of EAs, providing strong circumstantial evidence of the involvement of GR in the EAsinduced NF- $\kappa \mathrm{B}$ transcriptional inactivation.

\subsection{EAs induce mitochondrial impairment and mitochondrial dependent} apoptosis.

EAs-treated HeLa cells showed a decrease in the incorporation of the CMXROS mitochondrial dye when compared to the control DMSO treated cells (Fig. 5). This dye is exclusively incorporated into functional mitochondria of live cells. Therefore, this observation indicates that EAs can induce the depolarization of mitochondrial membrane and possibly a mitochondrial dysfunction in HeLa cells. In order to explore whether the EAs-induced mitochondrial impairment is also associated with induction of apoptosis, evaluation of caspase 3 and caspase 9 protein 
levels in EAs-treated HeLa cells was attempted by applying Western blot analysis. As shown in Figure 6, treatment of HeLa cells with $1 \mu \mathrm{M}$ DEX or $10 \mu \mathrm{M}$ EAs, for 48-72 hrs, did not cause significant changes in procaspases -3 and -9 protein levels. Nevertheless, combined addition of $1 \mu \mathrm{M}$ DEX and $10 \mu \mathrm{M}$ EAs in HeLa cells caused proteolytic activation of both caspase 3 and caspase 9, as indicated by the 2-3 fold reduction in procaspases protein levels compared to control cells. This implies that an additive effect of EAs and DEX on induction of mitochondrial dependent apoptosis may occur. Similar results were obtained as regards the protein levels of the antiapoptotic molecule Bcl-2. Incubation of HeLa cells with EAs in combination with DEX caused approximately 2 fold reduction in Bcl-2 protein levels compared to controls. RU 486, a DEX antagonist, does not have any influence on the effect of EAs on the expression of apoptosis related GR target genes (Fig. 6).

\subsection{Induced-fit docking results.}

Induced-fit docking of DEX, DAC, EA and EA-3G to GR was performed using the solved GR LBD bound to DAC as starting model. This crystal structure when solved revealed that the size of the ligand binding pocket is expanded to a size of $1070 \AA^{3}$, approximately double than the GR-DEX binding pocket $\left(540 \AA^{3}\right)$, and is better suited for the docking of bulkier ligands such as EA-3G studied here (SuinoPowell et al., 2008). The hypothesis was that EA-3G with its 3-O-glucoside can form an intricate network of interactions with the receptor in the upper-part of the ligand binding pocket while leaving the structure of the coactivator binding site intact, similar to that observed for the high affinity DAC ligand through its phenylpyrazole 
group (Suino-Powell et al., 2008). The IFD scoring results are shown in Table 1, with the EAs predicted to bind well in the LBD but less strongly than DEX and DAC.

The predicted binding interactions of EA and EA-3G are shown in Fig. 7. EA occupies close to the same space as DEX and its rings A-D are co-planar. The C3 $\mathrm{OH}$ group mimics interactions of the DEX C-3 headgroup ketone through hydrogen bonds with Gln570 (H3) and Arg611 (H5). Additionally, the C3 hydroxyl forms a hydrogen bond with Phe623 backbone O ( $\beta$-strand) between H5 and H6. There are no further hydrogen bonding interactions with H3. The C16 hydroxyl is not involved in hydrogen bonding interactions and is pointed towards $\mathrm{H} 7$ with shifting away of its Gln642 sidechain compared to the DEX bound structure; the C17 carboxylate is directed towards H11 exploiting a favourable interaction with Cys736 sidechain -SH. The mainly hydrophobic nature of EA means that the ligand exploits many favourable interactions with non-polar residues from different helices (Fig. 7B). For EA-3G, the 3-O-glucoside moiety protrudes into the upper part of the binding cavity in a similar manner as was observed for DAC but towards $\mathrm{H} 3$ rather than $\mathrm{H} 5$. The three glucopyranose hydroxyls are engaged in a number of hydrogen bonding interactions: two parallel hydrogen bonds with Arg611 (H5) sidechain NH's and additional hydrogen bonds with Pro541 O from the loop preceding H1. With the important Gln570 residue, a hydrogen bond contact is strained (non-ideal angles) and its H3 sidechain is pushed away, the potential significance of which is discussed later. The network of interactions formed by the glucopyranose moiety leads to an adjustment in the orientation of the ligand core compared to EA so that it is no longer co-planar with DEX. While the ligand core scaffold retains numerous favourable interactions with non-polar residues, the $\mathrm{C} 17$ carboxylate group now occupies the position of the $\mathrm{C} 16$ hydroxyl for EA binding and further pushes the Gln642 (H7) sidechain parallel to the 
helix rather than the perpendicular orientation observed in the GR-DEX LBD complex (also discussed further below). The C16 hydroxyl is directed towards Asn564 but does not hydrogen bond in the predicted model.

Table 1: Induced-fit docking calculation results ${ }^{\mathrm{a}}$

\begin{tabular}{lll}
\hline Ligand & GlideScore & IFDscore \\
\hline DAC & -17.44 & -556.40 \\
DEX & -15.89 & -552.09 \\
EA-3G & -13.20 & -549.69 \\
EA & -11.28 & -540.38 \\
\hline
\end{tabular}

${ }^{\mathrm{a}}$ Scores for top-ranked poses based on the IFDscores.

\section{Discussion}

Glucocorticoids, regulate intermediate metabolism, growth, development, stress, immune response, and apoptosis via their cognate receptors, via genomic and non-genomic mechanisms of actions (Barnes, 1998; Sapolsky et al., 2000). Genomic actions of GCs, results in positive or negative regulation of the expression of a plethora of genes, through direct binding of GR to positive or negative glucocorticoid responsive elements (GREs) or through physical interactions of GRs with other transcription factors. Cortisol is the most abundant endogenous glucocorticoid in human subjects, produced under the control of HPA axis (Evans, 1988). Among the cortisol-positively regulated target genes are genes encoding lipoprotein receptors and enzymes of glucose, lipid, amino acid metabolism and anti-inflammatory protein, while negatively regulated genes are genes encoding $\mathrm{CRH}$, proopiomelanocortin, 
adiponectin, and pro-inflammatory cytokines (Dostert and Heinzel, 2004; DegawaYamauchi et al., 2005, Rose and Herzig, 2013). Besides, by physical interaction of GR with other transcription factors, such as NF- $\kappa B$, cortisol negatively regulates the expression of many inflammatory cytokines, which constitute NF- $\mathrm{B}$ target genes (Liberman et al., 2007; Psarra and Sekeris, 2008). Thus, cortisol affects human metabolism as well as human immune responses (Bamberger et al., 1996; Dostert and Heinzel, 2004; Degawa-Yamauchi et al., 2005; Wang, 2005; Rose and Herzig, 2013; Oppong and Cato, 2015). Due to the anti-inflammatory actions of cortisol, GCs as well as synthetic glucococorticoids, are widely used in medicine to treat inflammatory diseases and autoimmune disorders (Buttgereit et al., 2015). Despite the favorable anti-inflammatory actions of GCs, the chronic use of them, as therapeutic drugs, give rise to many side effects. In addition, patients receiving long term glucocorticoid therapy, frequently have tissue-specific glucocorticoid resistance (Yang and Ray, 2013). Thus there is a high need for the discovery of glucocorticoid activators with reduced side effects.

Certain echinocystic acids exert anti-inflammatory, anti-apoptotic, antidepression, osteoprotective and anti-diabetic activities (Kumar et al., 2012; Deng et al., 2015; Li et al., 2016; Yang et al., 2016). The molecular mechanisms of these actions are not clearly defined. It is proposed that the anti-inflammatory action of EAs is mediated through NF- $\kappa \mathrm{B}$ inactivation. Thus, echinocystic acid is shown to suppress the lipopolysaccharide- and the IL-1 $\beta$ - induced iNOS, and to inhibit pro-inflammatory cytokines expression, IL- 6 , IL-1 $\beta$ and TNF- $\alpha$, via inhibition of IKK $\beta$ phosphorylation and/or NF- $\mathrm{KB}$ inactivation in several type of cells, particularly in macrophages (Ryu et al., 2013; Hyam et al., 2013; Joh et al., 2014, Ma et al., 2016). In addition, echinocystic acid is shown to inhibit the TPA-induced myeloperoxidase activity, (Joh 
et al., 2014) and to down-regulate the expression of nitric oxide synthase, cyclooxygenase-2, and that of the inflammatory mediators, nitric oxide and prostaglandin E2, (Gene et al., 1996; Joh et al., 2012, Ma et al., 2016).

Likewise GCs are known to exert anti-inflammatory activity, through suppression of NF- $\mathrm{KB}$ activity, pro-inflammatory cytokines and cyclooxygenase expression and through inhibition of prostaglandin synthesis at the level of phospholipase A2 as well as at the level of cyclooxygenase/PGE isomerase (COX-1 and COX-2) (Goppelt - Struebe et al., 1989; Baschant et al., 2013;).

Since GCs and EAs share common anti-inflammatory activities, our aim has been to identify whether EAs are able to mediate their actions, at least in part, through activation of GR trans-repressional activities and ideally with preferentially little or no effect on trans-activating GR activities. Our results clearly show that echinocystic acid and its 3-O glucoside are able to induce $75 \%$ and $55 \%$, nuclear translocation of GR, indicating that the structural similarities of EAs with GCs enable them to bind to cytosolic GR and to trigger its nuclear translocation and activation.

EAs-induced nuclear translocation of GR does not end up in its transcriptional activation, as indicated by the assessment of EAs-induced activation of the GREdriven luciferase gene expression. Consistent with this observation was the finding that the PEPCK expression, that constitute a well-known GR target gene, and a key regulatory enzyme of gluconeogenesis, remained unaffected in response to EAs treatment. The inability of EAs to induce PEPCK gene expression might be attributed to the EAs-induced GR conformational changes that do not favor (in the case of EA) or restrict (by $60 \%$ compared to DEX, in the case of EA-3G) GR binding to the promoter region of the PEPCK gene, as indicated by ChIP analysis. Interestingly, EAs could act as DEX antagonists as indicated by the EA- and EA-3G- induced reduction 
(by $100 \%$ and $60 \%$, respectively) in the DEX-induced increase in PEPCK protein level and the EAs-induced moderate reduction in the DEX-induced GR transcriptional activation. RU 486, which is a DEX antagonist, did not alter the EAs effect on glucocorticoid receptor target gene expression. The relative limited induction of protein expression of PEPCK by DEX, compared to controls, could be attributed to the observed DEX-induced decrease in GR protein levels. This effect, which is also observed by others (Shimojo et al., 1995; Cidlowski and Cidlowski, 1981) may be assigned to the NCoR1 complex-mediated ligand-induced repression of the glucocorticoid receptor gene (Ramamoorthy and Cidlowski, 2013).

Although unable to induce transcription of the GRE-regulated genes, EAsinduced nuclear translocation of GR was accompanied with suppression of the TNF- $\alpha$ -induced NF- $\kappa \mathrm{B}$ activation in HeLa GR-positive cells. The EAs inhibitory effect on $\mathrm{NF}-\kappa \mathrm{B}$ transcriptional activation was shown in both the non- and the TNF $\alpha$ sensitized HeLa cells. This effect appears to be exerted at the transcriptional level, since there were no changes observed in the levels of the p65 subunit of NF- $\kappa B$ in EAs-treated HeLa cells compared to controls. Interestingly, $10 \mu \mathrm{M}$ EA-3G are as effective as $1 \mu \mathrm{M}$ DEX in the reduction of the NF- $\kappa \mathrm{B}$ transcriptional activity, exhibiting more than $40 \%$ inhibition, whereas, $10 \mu \mathrm{M}$ of the echinocystic acid induced weaker (20\%), compared to DEX, suppression of the NF- $\kappa \mathrm{B}$ activity. Moreover, the EAs suppressive action on the TNF $\alpha$-induced NF- $\kappa \mathrm{B}$ activity is approximately doubled in the presence of DEX, in HeLa cells either expressing endogenous GR levels or transiently overexpressing the glucocorticoid receptor, in comparison to control cells. The inhibitory effect of EAs on the NF- $\kappa \mathrm{B}$ activity is abolished in GR low level COS-7 cells, further supporting the involvement of GR in this process. Although EA is more effective in the induction of the GR nuclear 
translocation, the glucoside moiety of the EA-3G molecule might cause conformational changes that favor the GR-mediated NF- $\kappa B$ transcriptional inactivation, by affecting binding and requirement of other components of the multiprotein dynamic repression complex, as has been described for other dissociated molecules (Dezitter et al 2014, Sundahl et al 2015). Moreover, EAs compounds could differentially affect GR posttranscriptional modification, such as phosphorylation, crucial for fine regulation of GR activities. We also cannot exclude that EAs could possible act in an additional GR-independent manner.

The induced-fit docking calculations revealed a number of predictions consistent with the experimental observations. Both EA and EA-3G are predicted to bind in the LBD forming a number of key receptor-ligand interactions. Maintaining the location of helix H3 (and H4) has been cited (Liu et al., 2016) as more critical for GR nuclear translocation than the location of H12 on the basis that RU 486 can also trigger GR nuclear migration (Lewis-Tuffin et al., 2007); alternatively, it is generally accepted that the location of $\mathrm{H} 12$ is critical to the release of the GR complex from its HSP chaperone (Liu et al., 2016; Bledsoe et al., 2002). Neither of the top-ranked IFD poses for EA or EA-3G are predicted to hydrogen bond with Asn564 (H3), an important contact observed for steroid agonists and proposed as favourable for nuclear translocation by holding $\mathrm{H} 3$ in its canonical position. EA-3G has also predicted contacts that are strained with Gln570 (H3). Taken together, these binding features could be a source of the weaker EA-3G translocation (55\%) compared to its aglycone EA analogue (75\%) and when compared to DEX (100\%). Equally, the pushing away of Gln642 in $\mathrm{H} 7$ by the $\mathrm{C} 17$ carboxylate of EA-3G could be a contributing factor to its observed promising (transrepressional) activity (EA-3G $\approx$ DEX > EA) through possible stabilization effects on the $\mathrm{H} 12$ position, in a manner 
previously reported for the highly potent synthetic glucocorticoid, mometasone furoate (He et al., 2014). The predicted binding affinities of EA-3G and EA are similar but less than for DEX. This lends support to the antagonistic effect of these ligands on DEX activity which is consistent with the lower PEPCK levels observed for DEX in the presence of the EAs. The proposed hypotheses while consistent with the experimental observations are based on docking models. The key factor in glucocorticoid physiology is what ligand dependent structural reorganizations of the GR LBD allow a receptor to function as a more potent activator. High ligand binding affinity for the receptor is a determining factor in potency but cellular co-factors also play important roles through recognition of the surface conformational changes caused by binding of different ligands (He et al., 2014). Subtle induced changes can have profound effects on cofactor selectivity.

In addition to their anti-inflammatory actions, GCs are well known for their cell type specific effect on induction of apoptosis (Gruver-Yates and Cidlowski, 2013) that give rise to their use as anticancer agents, in the treatment of specific type of cancers (Pufall, 2015). The molecular mechanisms of the GCs-mediated induction of apoptosis involve down regulation or inhibition of anti-apoptotic molecules, such as Bcl-2, as well as upregulation or activation of pro-apoptotic molecules such as BAX-2 (Lotem and Sachs, 1995; Salomons et al., 1997; Rieger et al., 1999; Murphy et al., 2000; Das et al., 2004; Almawi et al., 2004; Hoijman et al., 2004; Mahmoud et al., 2009; Lopez-Royuela et al., 2010; Melarangi et al., 2012; Zaman et al., 2014). The mitochondrial dependent induction of apoptosis by DEX has been observed in several types of cells. In accordance with the GC-driven induction of apoptosis, HeLa cells treated with EAs showed alterations in mitochondrial membrane potential, as indicated by the reduced accumulation of the CMX dye. These alternations resulted in 
mitochondrial dependent apoptosis, as proved by the two to three reduced level of procaspase $-9,-3$ and Bcl-2 when EAs are used in combination with DEX. These observations are in accordance with the EAs induction of apoptosis in hematopoietic, HepG2 cells and human ovarian cancer cells at concentrations higher than $20 \mu \mathrm{M}$ (Tong et al., 2004a, 2004b; Lee et al., 2005, Kim et al., 2015, Cho et al., 2016). The additive effect of $10 \mu \mathrm{M}$ EAs and $1 \mu \mathrm{M}$ DEX on the NF- $\kappa \mathrm{B}$ transcriptional inactivation and the induction of apoptosis at concentration lower than that reported in the literature may have an important role in immunosuppressive and anticancer combinations therapy, which aims at minimizing side effects of any single drug.

In conclusion, EAs showed anti-inflammatory and apoptotic activities that are predicted to be mediated by binding of EAs to GR and triggering its nuclear translocation. EAs-induced GR nuclear localization interferes with GR signalling, resulting in dissociation of GR transactivation from transrepression as indicated by the activation of GR transrepressional activities on NF- $\kappa B$ activity and the negative effect of EAs on the expression of GR target genes, involved in glucose metabolism and in the GCs-induced apoptosis (Fig. 8). Since EAs could favor GR tranrepression over transactivation, they could be considered as selective glucocorticoid receptor activators, at least as regards reduction of the side effect of gluconeogenesis. Further analysis is required to delineate their mechanisms of actions and to explore, their potential for therapeutic use as anti-inflammatory and anticancer drug, with reduced side effects, alone or in combination with DEX, in vivo models.

\section{Acknowledgements}

This work was supported by the Bodossaki Foundation (to AMGP) and funded by the European Union's Seventh Framework Programme FP7/2007-2013/ under REA grant 
agreement $\mathrm{n}^{\circ}$ [613692]- TRIFORC (to KKP) and in part by the Postgraduate Programmes "Biotechnology-Quality assessment in Nutrition and the Environment", “Application of Molecular Biology-Molecular Genetics-Molecular Markers”, Department of Biochemistry and Biotechnology, University of Thessaly (to AMGP and KKP). We would like also to thank Dr. M. Alexis for kindly provided us with the 2F8 glucocorticoid receptor monoclonal antibody 


\section{Figures Legends}

\section{Figure 1.}

Chemical structures of synthetic glucocorticoids DEX and DAC (GR agonists), the synthetic antiglucocorticoid RU 486 (GR antagonist), together with EA and its 3-Oglucoside analogue EA-3G studied in this work.

\section{Figure 2.}

EA and its 3-O glucoside induced GR nuclear translocation in HeLa cells. HeLa cells cultured in hormone depleted medium for $48 \mathrm{hrs}$ were incubated with $10 \mu \mathrm{M}$ EAs (diluted in DMSO) or $1 \mu \mathrm{M}$ DEX (diluted in EtOH). Control cells were treated with DMSO and EtOH at the same dilution as treated cells. Following $2 \mathrm{hrs}$ incubation cells were washed in PBS and fixed in methanol-acetone. For immunochemistry analysis antibodies against GR (GR-H300) and anti-rabbit secondary antibodies Alexa Fluor ${ }^{\circledR} 488$ conjugated (Green) were applied. Hoechst 33342 (Blue) dye for nuclear staining was also used. Bars indicate $30 \mu \mathrm{M}$. Relative GR nuclear localization is expressed as percentage of mean intensity of GR nuclear staining per mean intensity of total GR cellular staining. Data are expressed as mean \pm S.D. $(\mathrm{n}>30), * * * \mathrm{P}<0.001$, compared to controls.

\section{Figure 3.}

EAs do not induce GR transcriptional activation in HeLa cells. A. HeLa cells cultured in hormone depleted medium were transiently co-transfected with a GR-Luc reporter gene construct and a $\beta$-galactosidase reporter construct. Cells were further incubated for $48 \mathrm{hrs}$ and subsequently treated with $10 \mu \mathrm{M}$ EAs and/or $1 \mu \mathrm{M} \mathrm{DEX}$, for 6 hrs. Control cells were treated with DMSO (1:1000) and EtOH (1:1000). Cells were 
lysed and activity of luciferase and $\beta$-galactosidase was measured in cell extracts. Luciferase activity was normalized against $\beta$-galactosidase activity and expressed as relative luciferase unit. Data are expressed as mean \pm S.D. $(n=3), * * P<0.01$; $* * * \mathrm{P}<0.001$. B. Western blot analysis of PEPCK, GR, and $\beta$-actin protein levels was performed in extracts from HeLa cells treated with the indicated amounts of EAs, DEX, and or RU 486, in hormone depleted medium, for 48 hrs. Commercially provided antibodies were used. C. Normalization of PEPCK protein levels against $\beta$ actin and GR protein levels. D. Assessment of GR binding to the GRE of the promoter region of PEPCK gene in HeLa cells treated with $1 \mu \mathrm{M}$ DEX or $10 \mu \mathrm{M}$ EAs for 2 hrs. ChIP analysis was performed using the monoclonal 2F8 a-GR antibody. Immunoprecipitated DNA encompassing GRE of the promoter region of PEPCK gene was assessed by real-time PCR. Recovery of DNA was calculated as percentage of input material of the immunoprecipitation. Relative recovery was expressed as GR recovery of each sample compared to control. The results of three triplicate measurements of two independent experiments as means $\pm \mathrm{SD}$ are shown. $* \mathrm{P}<0.05$; $* * \mathrm{P}<0.01 ; * * * \mathrm{P}<0.001$

\section{Figure 4}

\section{EAs suppress NF-кB transcriptional activity in HeLa cells possibly through} regulations of GR signalling. A. HeLa cells cultured in hormone depleted medium were transiently co-transfected with a NF- $\mathrm{BB}$ Luc reporter gene construct and a $\beta$ galactosidase reporter construct. Cells were further incubated for $48 \mathrm{hrs}$ and subsequently treated with $10 \mu \mathrm{M}$ EAs or DMSO (Control) and/or $10 \mathrm{nM}$ TNF $\alpha$, for 6 hrs. Cells were lysed and activity of luciferase and $\beta$-galactosidase was measured in cell extracts. Luciferase activity was normalized against $\beta$-galactosidase activity and 
expressed as relative luciferase units. Effect of EAs on NF- $\mathrm{B}$ activity was also evaluated in HeLa GFP or GFP-GR overexpressing cells, in the presence or absence of DEX (B) or in low level GR expressing COS-7 cells (C). Data are expressed as mean \pm S.D. $(n=3-5)$ and analyzed by analysis of variance followed by Tukeys's posthoc test $(* \mathrm{P}<0.05 ; * * \mathrm{P}<0.01 ; * * * \mathrm{P}<0.001)$. D. Western blot analysis of the p65 subunit of NF- $\kappa \mathrm{B}$ in HeLa EAs and/or DEX treated cells. $\beta$-actin protein levels was examined for the normalization of the results. Commercially provided antibodies against $\mathrm{p} 65$ and $\beta$ - actin were used.

\section{Figure 5.}

\section{EAs induce mitochondrial dependent apoptosis.}

Fluorescence microscopy analysis of the CMXROS and Hoechst dye in EAs-treated HeLa cells revealed occasionally reduced incorporation of the CMXROS dye in mitochondria of EAs-treated cells compared to control cells (white arrows). Bars indicate $30 \mu \mathrm{M}$.

\section{Figure 6.}

\section{EAs in combination with DEX result in induction of apoptosis}

A. Western blot analysis of $\beta$-actin, Bcl2, pro-caspase 3 and pro-caspase 9 protein levels in cell extracts from HeLa cells treated with $10 \mu \mathrm{M}$ EAs and/or $1 \mu \mathrm{M}$ DEX, for $6 \mathrm{hrs}$ in hormone depleted medium, was performed using commercially provided antibodies. B. Mean intensity of Bcl-2, pro-caspase-3 and procaspase 9 protein levels normalized against $\beta$-actin protein levels. (Means $\pm \mathrm{SD}, \mathrm{n}=3$, *** $\mathrm{P}<0.001$ compared to relative controls). 


\section{Figure 7.}

Binding of (A) DEX (PDB code: 1M2Z) and (B) DAC (PDB code: 3BQD) to the GR LBD from their respective crystal structures, together with the predicted binding of (C) EA and (D) EA-3G from induced-fit docking calculations.

\section{Figure 8}

EAs as potent dissociated compounds for GR transrepression and transactivation.

A novel mechanism of EAs actions includes binding of EAs to GR and induction of its translocation from the cytoplasm to the nucleus. EAs - GR complex leads to dissociation of GR transrepression from transactivation. EAs favor activation of GR tranrepressional activities contributing to EAs anti-inflammatory actions (red box), whereas antagonistic or no effect of EAs on GCs-induced GR transactivation, leads to reduce GCs side effects (green box), at least as regards induction of the expression of the gluconeogenic enzyme PEPCK. In addition, EAs interfering with GCs signalling promotes mitochondrial dependent apoptosis. 


\section{References}

Almawi, W.Y., Melemedjian, O.K., Jaoude, M.M., 2004. On the link between Bcl-2 family proteins and glucocorticoid-induced apoptosis. J. Leukoc. Biol. 76, 7-14.

Bamberger, C.M., Schulte, H.M., Chrousos, G.P., 1996. Molecular determinants of glucocorticoid receptor function and tissue sensitivity to glucocorticoids. Endocr. Rev. 17, 245-261.

Barnes, P.J., 1998. Anti-inflammatory actions of glucocorticoids: molecular mechanisms. Clin. Sci. (Lond.) 94, 557-572.

Baschant, U., Culemann, S., Tuckermann, J., 2013. Molecular determinants of glucocorticoid actions in inflammatory joint diseases. Mol. Cell. Endocrinol. 380, 108-118.

Borski, R.J., 2000. Nongenomic membrane actions of glucocorticoids in vertebrates. Trends Endocrinol. Metab. 11, 427-436.

Bledsoe, R.K., Montana, V.G., Stanley, T.B., Delves, C.J., Apolito, C.J., McKee, D.D., Consler, T.G., Parks, D.J., Stewart, E.L., Willson, T.M., Lambert, M.H., Moore, J.T., Pearce, K.H., Xu, H.E., 2002. Crystal structure of the glucocorticoid receptor ligand binding domain reveals a novel mode of receptor dimerization and coactivator recognition. Cell 110, 93-105.

Bradford, M.M., 1976. A rapid and sensitive method for the quantitation of microgram quantities of protein utilizing the principle of protein-dye binding. Anal. Biochem. 72, 248-254.

Buttgereit, F., Spies, C.M., Bijlsma, J.W., 2015. Novel glucocorticoids: where are we now and where do we want to go? Clin. Exp. Rheumatol. 33(4 Suppl 92) S29-33. 
Cho, Y.J., Woo, J.H., Lee, J.S., Jang, D.S., Lee, K.T., Choi, J.H. 2016. Eclalbasaponin II induces autophagic and apoptotic cell death in human ovarian cancer cells. J. Pharmacol. Sci.

Cidlowski, J.A., Cidlowski, N.B., 1981. Regulation of glucocorticoid receptors by glucocorticoids in cultured HeLa S3 cells. Endocrinology 109, 1975-1982.

Das, A., Banik, N.L., Patel, S.J., Ray, S.K., 2004. Dexamethasone protected human glioblastoma U87MG cells from temozolomide induced apoptosis by maintaining Bax:Bcl-2 ratio and preventing proteolytic activities. Mol. Cancer 3, 36.

De Bosscher, K., Haegeman, G., Elewaut, D., 2010. Targeting inflammation using selective glucocorticoid receptor modulators. Curr. Opin. Pharmacol. 10, 497-504.

Degawa-Yamauchi, M., Moss, K.A., Bovenkerk, J.E., Shankar, S.S., Morrison, C.L., Lelliott, C.J., Vidal-Puig, A., Jones, R., Considine, R.V., 2005. Regulation of adiponectin expression in human adipocytes: effects of adiposity, glucocorticoids, and tumor necrosisfactor alpha. Obes. Res. 13, 662-669.

Deng, Y.T., Kang, W.B., Zhao, J.N., Liu, G., Zhao, M.G., 2015. Osteoprotective Effect of Echinocystic Acid, a Triterpone Component from Eclipta prostrata, in Ovariectomy-Induced Osteoporotic Rats. PLoS One 10, e0136572.

Dezitter, X., Fagart, J., Taront, S., Fay, M., Masselot, B., Hétuin, D., Formstecher, P., Rafestin-Oblin, M.E., Idziorek, T., 2014. A structural explanation of the effects of dissociated glucocorticoids on glucocorticoid receptor transactivation. Mol. Pharmacol. 85, 226-236.

Dostert, A., Heinzel T., 2004. Negative glucocorticoid receptor response elements and their role in glucocorticoid action. Curr. Pharm. Des. 10, 2807-2816.

Du, J., Wang, Y., Hunter, R., Wei, Y., Blumenthal, R., Falke, C., Khairova, R, Zhou R., Yuan, P., Machado-Vieira, R., McEwen, B.S., Manji, H.K., 2009. Dynamic 
regulation of mitochondrial function by glucocorticoids. Proc. Natl. Acad. Sci. U.S.A. $106,3543-3548$.

Evans, R.M., 1988. The steroid and thyroid hormone receptor superfamily. Science $240,889-895$.

Gené, R.M., Cartaña, C., Adzet, T., Marín, E., Parella, T., Cañigueral, S., 1996. Antiinflammatory and analgesic activity of Baccharis trimera: identification of its active constituents. Planta Med. 62, 232-235.

Goppelt-Struebe, M., Wolter, D., Resch, K., 1989. "Glucocorticoids inhibit prostaglandin synthesis not only at the level of phospholipase A2 but also at the level of cyclo-oxygenase/PGE isomerase". Br. J. Pharmacol. 98, 1287-1295.

Gruver-Yates, A.L., Cidlowski, J.A., 2013. Tissue-specific actions of glucocorticoids on apoptosis: a double-edged sword. Cells 2, 202-223.

Harder, E., Damm, W., Maple, J., Wu, C., Reboul, M., Xiang, J.Y., Wang, L., Lupyan, D., Dahlgren, M.K., Knight, J.L., Kaus, J.W., Cerutti, D.S., Krilov, G., Jorgensen, W.L., Abel, R., Friesner, R.A., 2016. OPLS3: A Force Field Providing Broad Coverage of Drug-like Small Molecules and Proteins. J. Chem. Theory Comput. 12, 281-296.

He, Y., Yi, W., Suino-Powell, K., Zhou, X.E., Tolbert, W.D., Tang, X., Yang, J., Yang, H., Shi, J., Hou, L., Jiang, H., Melcher, K., Xu, H.E., 2014. Structures and mechanism for the design of highly potent glucocorticoids. Cell Res. 24, 713-726.

Hoijman, E., Rocha Viegas, L., Keller Sarmiento, M.I., Rosenstein, R.E., Pecci, A., 2004. Involvement of Bax protein in the prevention of glucocorticoid-induced thymocytes apoptosis by melatonin. Endocrinology 145, 418-425. 
Hyam, S.R., Jang, S.E., Jeong, J.J., Joh, E.H., Han, M.J., Kim, D.H., 2013. Echinocystic acid, a metabolite of lancemaside A, inhibits TNBS-induced colitis in mice. Int. Immunopharmacol. 15, 433-441.

Joh, E.H., Gu, W., Kim, D.H., 2012. Echinocystic acid ameliorates lung inflammation in mice and alveolar macrophages by inhibiting the binding of LPS to TLR4 in NF$\kappa \mathrm{B}$ and MAPK pathways. Biochem. Pharmacol. 84, 331-340.

Joh, E.H., Jeong, J.J., Kim, D.H., 2014. Inhibitory effect of echinocystic acid on 12O-tetradecanoylphorbol-13-acetate-induced dermatitis in mice. Arch. Pharm. Res. 37, $225-231$

Kassel, O., Herrlich, P., 2007. Crosstalk between the glucocorticoid receptor and other transcription factors: molecular aspects. Mol. Cell. Endocrinol. 275, 13-29.

Kim, H.Y., Kim, H.M., Ryu, B., Lee, J.S., Choi, J.H., Jang, D.S. 2015. Constituents of the aerial parts of Eclipta prostrata and their cytotoxicity on human ovarian cancer cells in vitro. Arch. Pharm. Res. 38, 1963-1969.

Kleiman, A., Tuckermann, J.P., 2007. Glucocorticoid receptor action in beneficial and side effects of steroid therapy: lessons from conditional knockout mice. Mol. Cell. Endocrinol. 275(1-2), 98-108.

Kumar, D., Gaonkar, R.H., Ghosh, R., Pal, B.C., 2012. Bio-assay guided isolation of alpha-glucosidase inhibitory constituents from Eclipta alba. Nat. Prod. Commun. 7(8), 989-990.

Lee, K.W., Jung, H.J., Park, H.J., Kim, D.G., Lee, J.Y., Lee, K.T., 2005. Beta-Dxylopyranosyl-(1-->3)-beta-D-glucuronopyranosyl echinocystic acid isolated from the roots of Codonopsis lanceolata induces caspase-dependent apoptosis in human acute promyelocytic leukemia HL-60 cells. Biol. Pharm. Bull. 28, 854-859. 
Lewis-Tuffin, L.J., Jewell, C.M., Bienstock, R.J., Collins, J.B., Cidlowski, J.A., 2007. Human glucocorticoid receptor binds RU 486 and is transcriptionally active. Mol. Cell. Biol. 27, 2266-2282.

Li, S., Han, J., Wang, D.S., Feng, B., Deng, Y.T., Wang, X.S., Yang, Q., Zhao, M.G., 2016. Echinocystic acid reduces reserpine-induced pain/depression dyad in mice. Metab. Brain Dis. 31(2), 455-463.

Liberman, A.C., Druker, J., Perone, M.J., Arzt, E., 2007. Glucocorticoids in the regulation of transcription factors that control cytokine synthesis. Cytokine Growth Factor Rev. 18, 45-56.

Liu, Y-L, Jang S, Wang S-M, Chen C-H, Li F-Y., 2016. Investigation on critical structural motifs of ligands for triggering glucorticoid receptor nuclear migration through molecular docking simulations. J. Biomol. Struct. Dyn. 34, 1214-1231.

López-Royuela, N., Balsas, P., Galán-Malo, P., Anel, A., Marzo, I., Naval, J., 2010. Bim is the key mediator of glucocorticoid-induced apoptosis and of its potentiation by rapamycin in human myeloma cells. Biochim. Biophys. Acta 1803, 311-322.

Lotem, J., Sachs, L., 1995. Regulation of bcl-2, bcl-XL and bax in the control of apoptosis by hematopoietic cytokines and dexamethasone. Cell Growth Differ. 6, 647-653.

Ma, Z., Wang, Y., Piao, T., Liu, J., 2016. Echinocystic Acid Inhibits IL-1 $\beta$-Induced COX-2 and iNOS Expression in Human Osteoarthritis Chondrocytes. Inflammation $39,543-549$.

Mahmoud, H., Mahmoud, O., Layasadat, K., Naeim, A., 2009. Dexamethasone effects on Bax expression in the mouse testicular germ cells. Folia Histochem. Cytobiol. 47, 237-241. 
Melarangi, T., Zhuang, J., Lin, K., Rockliffe, N., Bosanquet, A.G., Oates, M., Slupsky, J.R., Pettitt, A.R. 2012. Glucocorticoid resistance in chronic lymphocytic leukaemia is associated with a failure of upregulated $\mathrm{Bim} / \mathrm{Bcl}-2$ complexes to activate Bax and Bak. Cell Death Dis 3, e372.

Murphy, K.M., Ranganathan, V., Farnsworth, M.L., Kavallaris, M., Lock, R.B., 2000. Bcl-2 inhibits Bax translocation from cytosol to mitochondria during drug-induced apoptosis of human tumor cells. Cell Death Differ. 7, 102-111.

Oakley, R.H., Cidlowski, J.A., 2013. The biology of the glucocorticoid receptor: new signaling mechanisms in health and disease. J. Allergy Clin. Immunol. 132, 10331044.

Oppong, E., Cato, A.C., 2015. Effects of Glucocorticoids in the Immune System. Adv. Exp. Med. Biol. 872, 217-233.

Psarra, A.M., Hermann, S., Panayotou, G., Spyrou, G., 2009. Interaction of mitochondrial thioredoxin with glucocorticoid receptor and NF-kappaB modulates glucocorticoid receptor and NF-kappaB signalling in HEK-293 cells. Biochem. J. 422, $521-531$

Psarra, A.M., Sekeris, C.E., 2009. Glucocorticoid receptors and other nuclear transcription factors in mitochondria and possible functions. Biochim. Biophys. Acta 1787, 431-436.

Psarra, A.M., Sekeris, C.E., 2011. Glucocorticoids induce mitochondrial gene transcription in HepG2 cells: role of the mitochondrial glucocorticoid receptor. Biochim. Biophys. Acta 1813, 1814-1821.

Psarra, A.M., Sekeris, C.E., 2008. Nuclear receptors and other nuclear transcription factors in mitochondria: regulatory molecules in a new environment. Biochim. Biophys. Acta 1783, 1-11. 
Psarra, A.M., Solakidi, S., Trougakos, I.P., Margaritis, L.H., Spyrou, G., Sekeris, C.E., 2005. Glucocorticoid receptor isoforms in human hepatocarcinoma HepG2 and SaOS-2 osteosarcoma cells: presence of glucocorticoid receptor alpha in mitochondria and of glucocorticoid receptor beta in nucleoli. Int. J. Biochem. Cell Biol. 37, 25442558.

Pufall, M.A., 2015. Glucocorticoids and Cancer. Adv. Exp. Med. Biol. 872, 315-333. Ramamoorthy, S., Cidlowski, J.A., 2013. Ligand-induced repression of the glucocorticoid receptor gene is mediated by an $\mathrm{NCoR} 1$ repression complex formed by long-range chromatin interactions with intragenic glucocorticoid response elements. Mol. Cell. Biol. 33, 1711-1722.

Refojo, D., Liberman, A.C., Holsboer, F., Arzt, E., 2001. Transcription factormediated molecular mechanisms involved in the functional cross-talk between cytokines and glucocorticoids. Immunol. Cell Biol. 79, 385-394.

Rieger, J., Durka, S., Streffer, J., Dichgans, J., Weller, M., 1999. Gemcitabine cytotoxicity of human malignant glioma cells: modulation by antioxidants, BCL-2 and dexamethasone. Eur. J. Pharmacol. 365, 301-308.

Rose, A.J., Herzig, S., 2013. Metabolic control through glucocorticoid hormones: an update. Mol. Cell. Endocrinol. 380, 65-78.

Ryu, S., Shin, J.S., Jung, J.Y., Cho, Y.W., Kim, S.J., Jang, D.S., Lee, K.T., 2013. Echinocystic acidisolated from Eclipta prostrata suppresses lipopolysaccharideinduced iNOS, TNF- $\alpha$, and IL-6 expressions via NF- $\kappa$ B inactivation in RAW 264.7 macrophages. Planta Med. 79, 1031-1037.

Salomons, G.S., Brady, H.J., Verwijs-Janssen, M., Van Den Berg, J.D., Hart, A.A., Van Den Berg, H., Behrendt, H., Hählen, K., Smets, L.A., 1997. The Bax alpha:Bcl-2 
ratio modulates the response to dexamethasone in leukaemic cells and is highly variable in childhood acute leukaemia. Int. J. Cancer 71, 959-965.

Sapolsky, R.M., Romero, L.M., Munck, A.U., 2000. How do glucocorticoids influence stress responses? Integrating permissive, suppressive, stimulatory, and preparative actions. Endocr. Rev. 21, 55-89.

Schmidt, S., Rainer, J., Ploner, C., Presul, E., Riml, S., Kofler, R., 2004. Glucocorticoid-induced apoptosis and glucocorticoid resistance: molecular mechanisms and clinical relevance. Cell Death Differ. 11 (Suppl 1), S45-55.

Schrodinger, L.L.C., 2016. Modeling Software Suite. New York.

Sherman, W., Day, T., Jacobson, M.P., Friesner, R.A., Farid, R., 2006. Novel procedure for modeling ligand/receptor induced fit effects. J. Med. Chem. 49, 534553.

Shimojo, M., Hiroi, N., Yakushiji, F., Ueshiba, H., Yamaguchi, N., Miyachi, Y., 1995. Differences in down-regulation of glucocorticoid receptor mRNA by cortisol, prednisolone and dexamethasone in HeLa cells. Endocr. J. 42, 629-636.

Sionov, R.V., Cohen, O., Kfir, S., Zilberman, Y., Yefenof, E., 2006. Role of mitochondria glucocorticoid receptor in glucocorticoid-induced apoptosis. J. Exp. Med. 203, 189-201.

Suino-Powell, K., Xu, Y., Zhang, C., Tao, Y., Tolbert, W.D., Simons Jr S.S., Xu, H.E., 2008. Doubling the size of the glucocorticoid receptor ligand binding pocket by deacylcortivazol. Mol. Cell. Biol 28, 1915-1923.

Sundahl, N., Bridelance, J., Libert, C., De Bosscher, K., Beck, I.M., 2015. Selective glucocorticoid receptor modulation: New directions with non-steroidal scaffolds. Pharmacol. Ther. 152, 28-41. 
Tong, X., Lin, S., Fujii, M., Hou, D.X., 2004a. Echinocystic acid induces apoptosis in HL-60 cells through mitochondria-mediated death pathway. Cancer Lett. 212, 21-32. Tong, X., Lin, S., Fujii, M., Hou, D.X. 2004b. Molecular mechanisms of echinocystic acid-induced apoptosis in HepG2 cells. Biochem. Biophys. Res. Commun. 321, 539546.

Vandevyver, S., Dejager, L., Tuckermann, J., Libert, C., 2013. New insights into the anti-inflammatory mechanisms of glucocorticoids: an emerging role for glucocorticoid-receptor-mediated transactivation. Endocrinology 154, 993-1007.

Wang, M., 2005. The role of glucocorticoid action in the pathophysiology of the Metabolic Syndrome. Nutr Metab (Lond) 2, 3.

Yang, N., Ray, D.W., Matthews, L.C., 2012. Current concepts in glucocorticoid resistance. Steroids 77, 1041-1049.

Yang, J.H., Li, B., Wu, Q., Lv, J.G., Nie, H.Y., 2016. Echinocystic acid inhibits RANKL-induced osteoclastogenesis by regulating NF-kappaB and ERK signaling pathways. Biochem. Biophys. Res. Commun.

Zaman, F., Chrysis, D., Huntjens, K., Chagin, A., Takigawa, M., Fadeel, B., Sävendahl, L., 2014. Dexamethasone differentially regulates Bcl-2 family proteins in human proliferative chondrocytes: role of pro-apoptotic Bid. Toxicol. Lett. 224, 196200. 

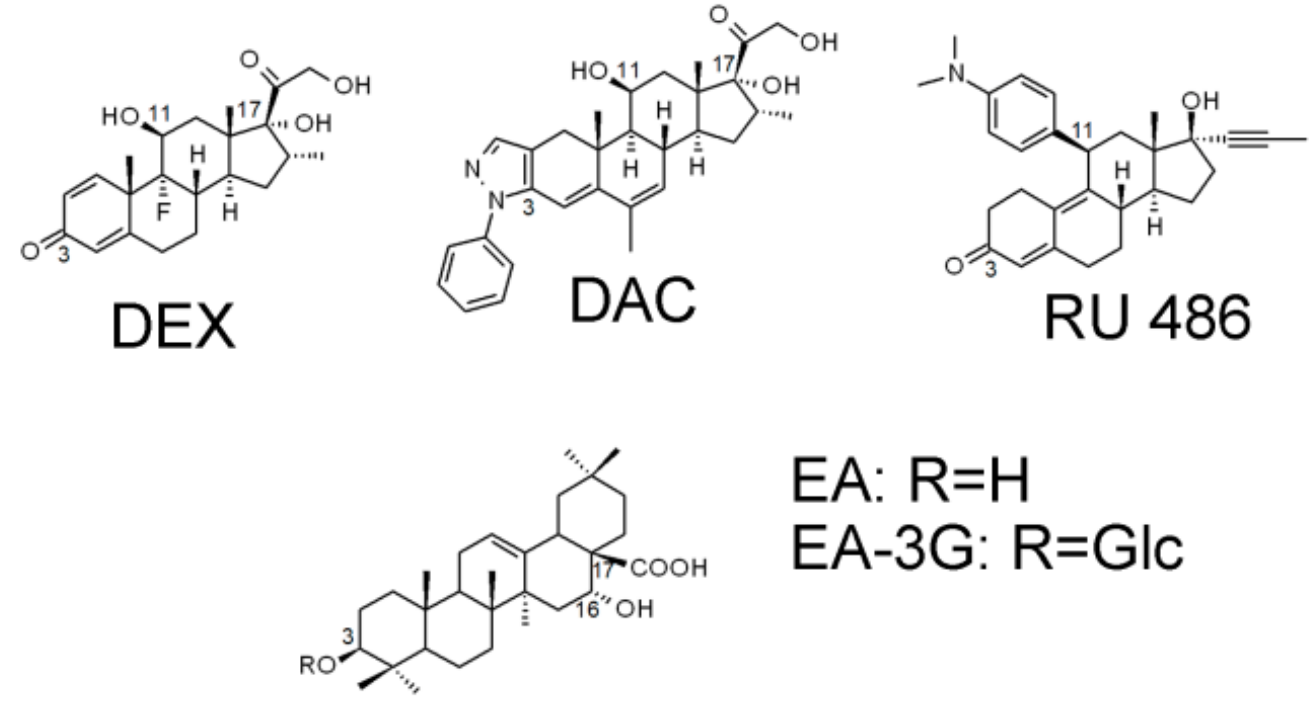

Figure 1
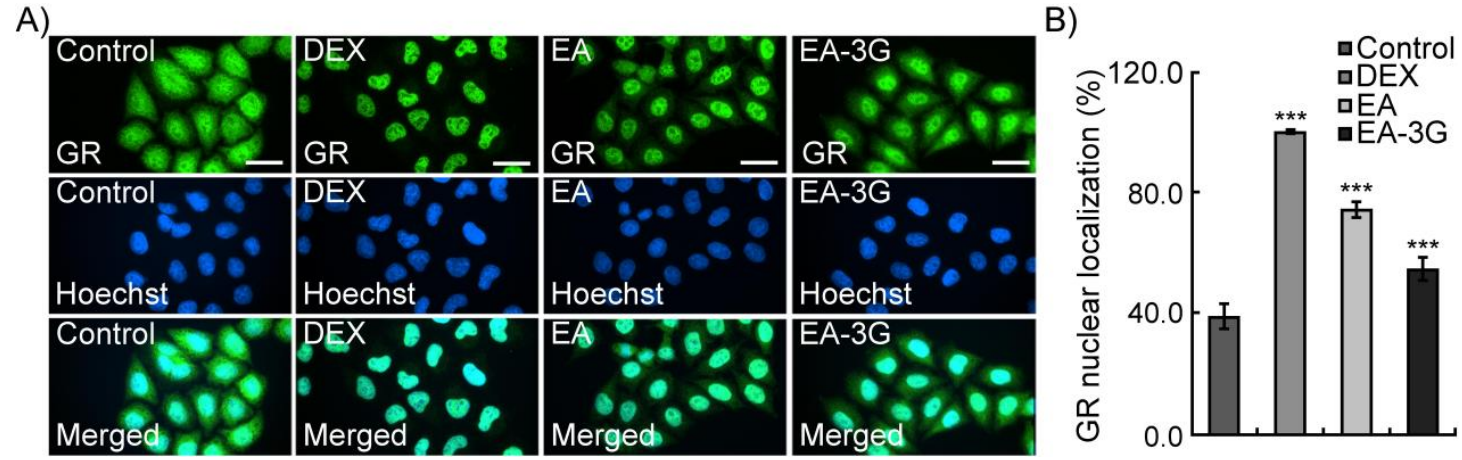

Figure 2 
A)

B)

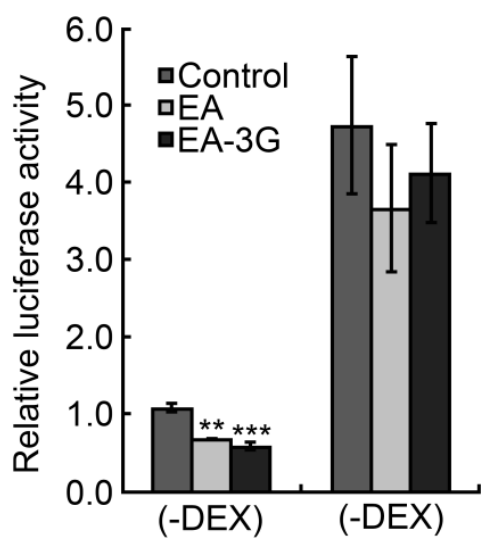

GR

PEPCK

$\beta$ - actin

DEX $-+\quad-+\quad+\quad+\quad-$

$\mathrm{EA} \quad-\quad-++-\quad-\quad+\quad-$

EA-3G - $-\quad-\quad-\quad+\quad+\quad-\quad-$

$\mathrm{RU} 486 \quad-\quad-\quad-\quad-\quad-\quad-\quad+\quad+$

C) $\quad \begin{array}{llllllllll}1.0 & 1.9 & 0.9 & 1.0 & 0.8 & 1.2 & 1.1 & 1.2 & 0.8\end{array}$

D)

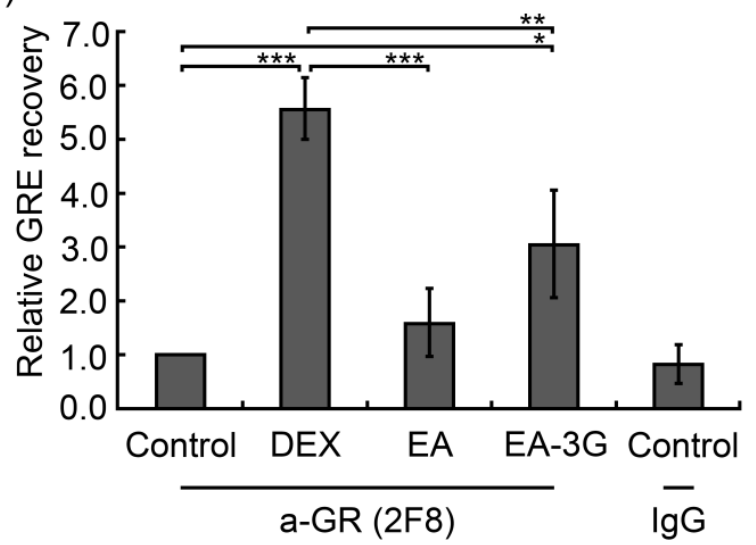

Figure 3 
A)

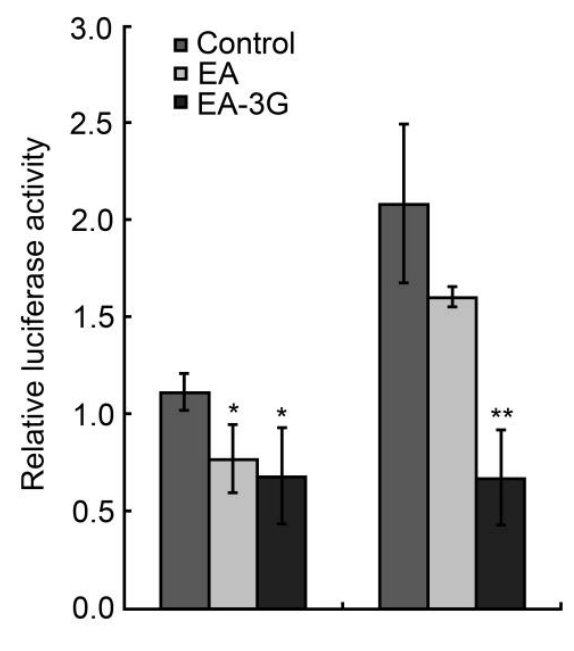

C)

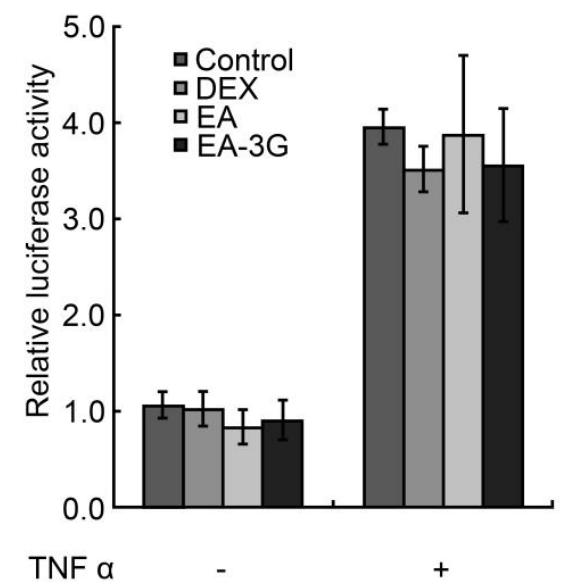

Figure 4
B)

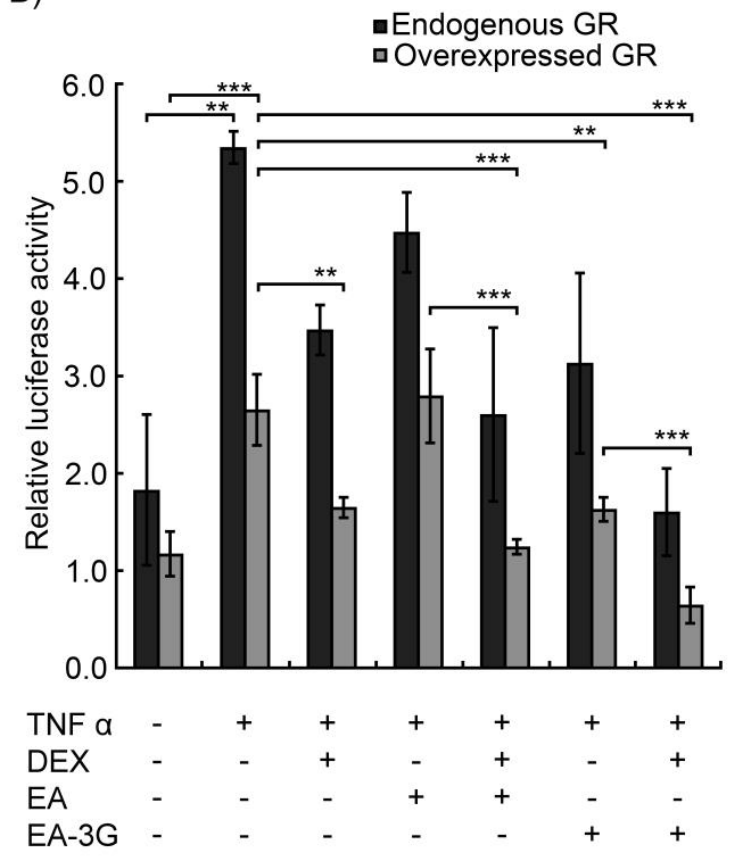

D)

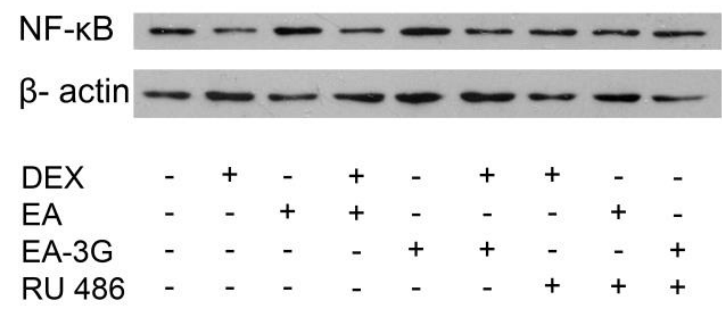




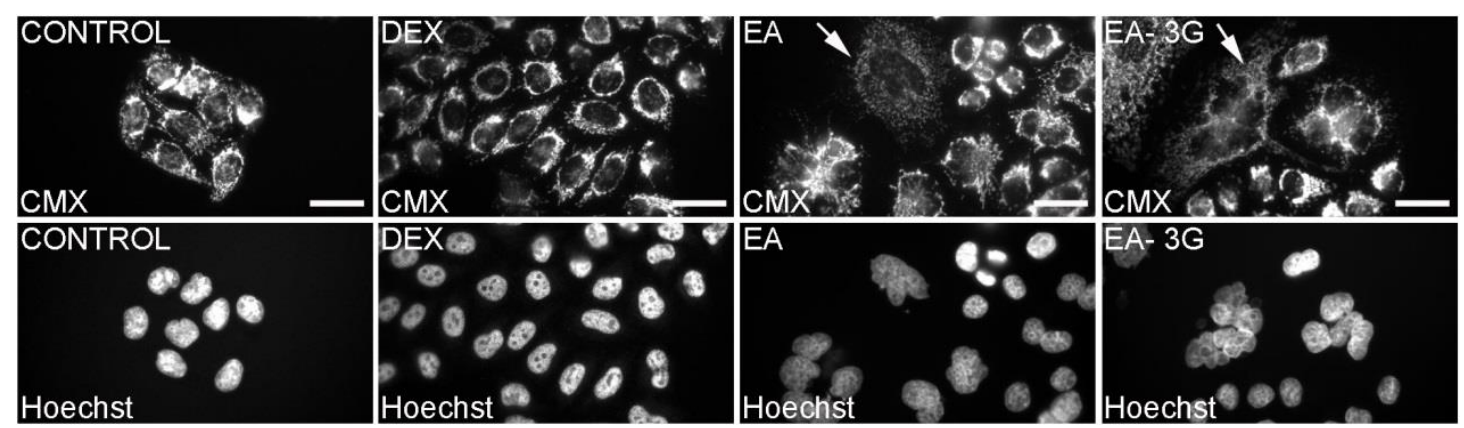

Figure 5

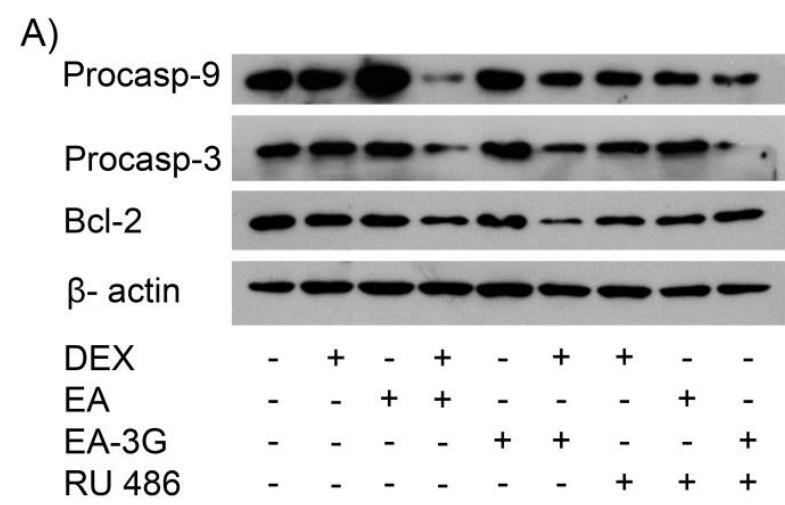

B)
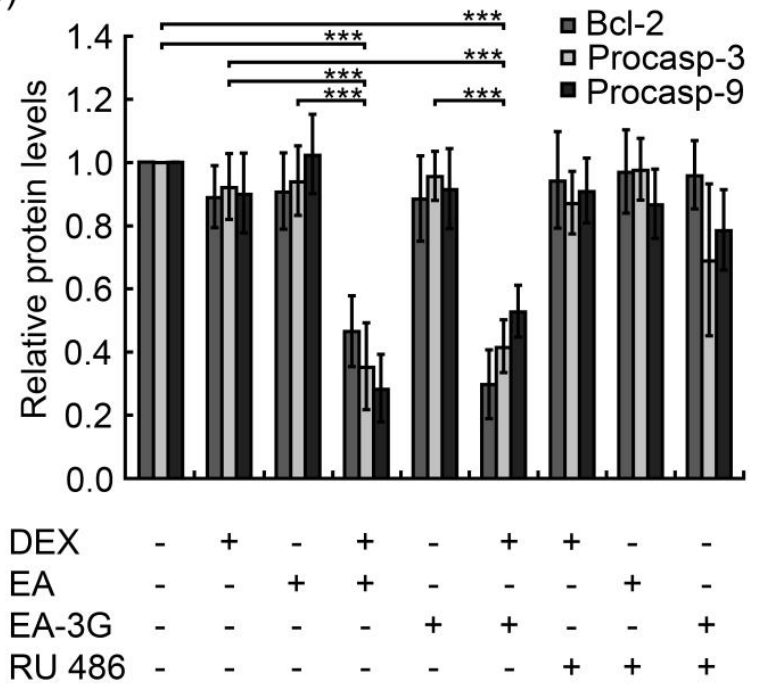

Figure 6 
(A)

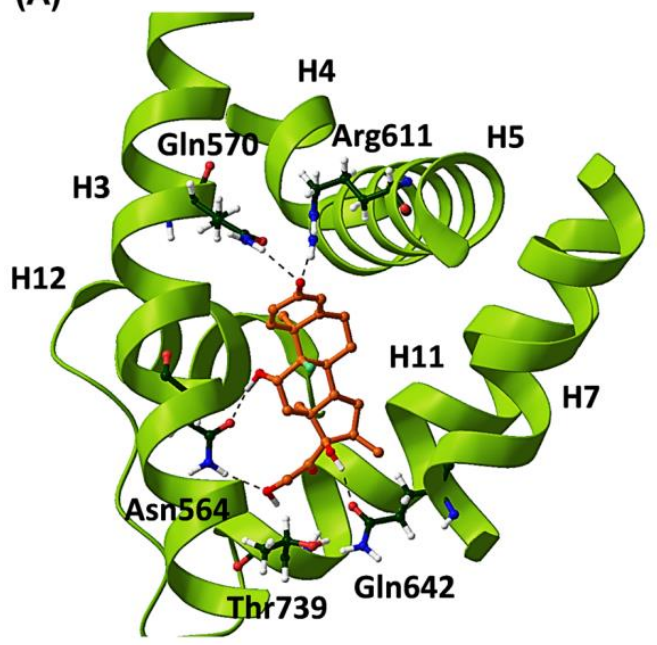

(C)

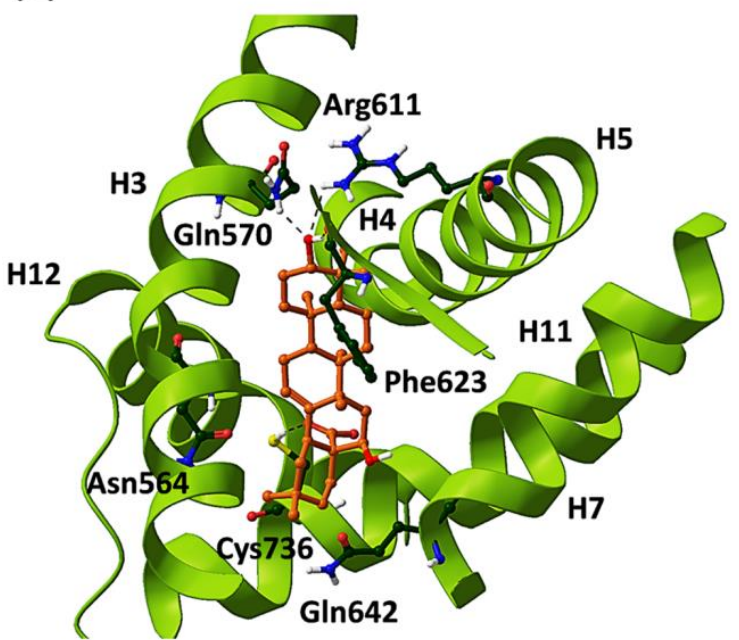

(B)

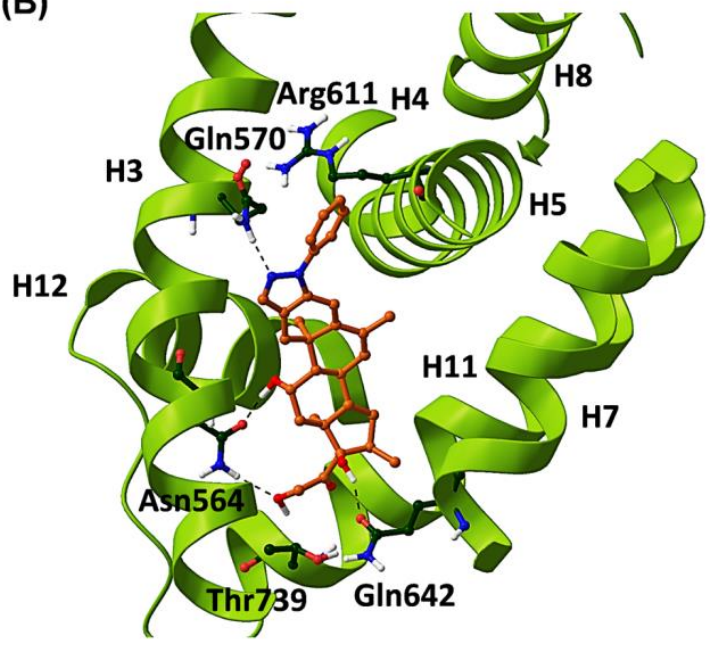

(D)

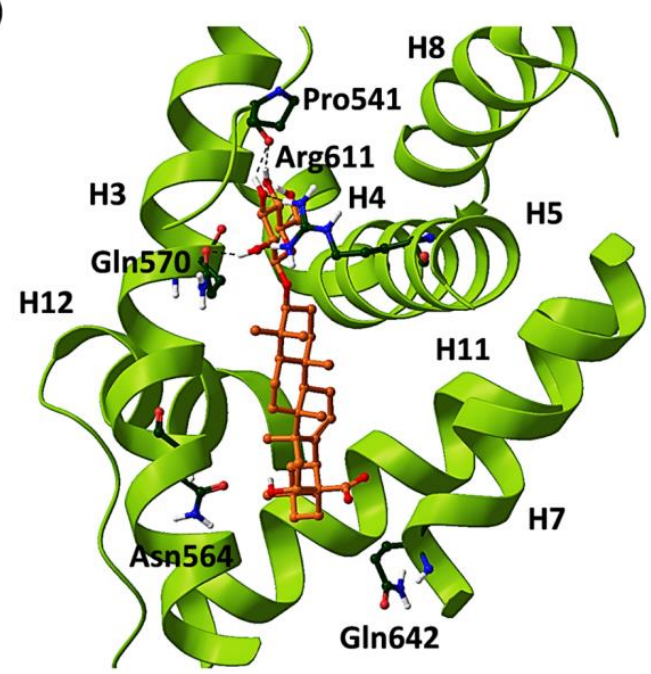

Figure 7

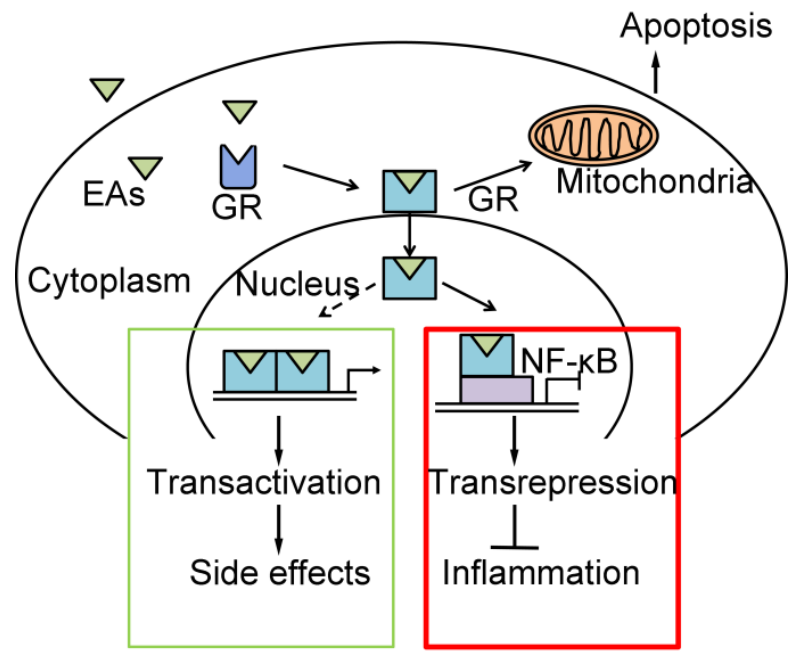

Figure 8 
A)

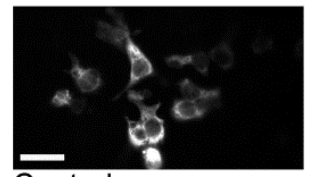

Control

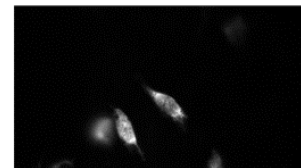

$1 \mu \mathrm{M} E \mathrm{~A}$

B)

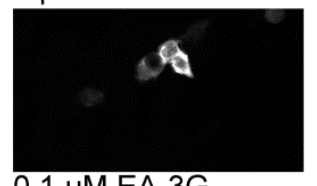

$0.1 \mu \mathrm{M}$ EA-3G

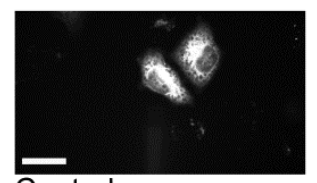

Control

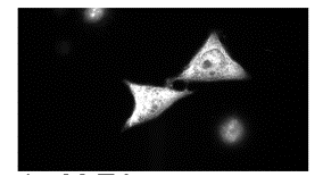

$1 \mu \mathrm{MEA}$

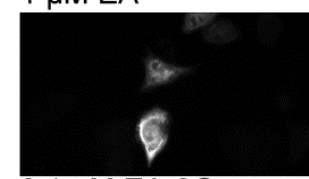

$0.1 \mu \mathrm{M}$ EA-3G

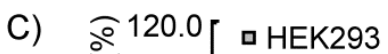

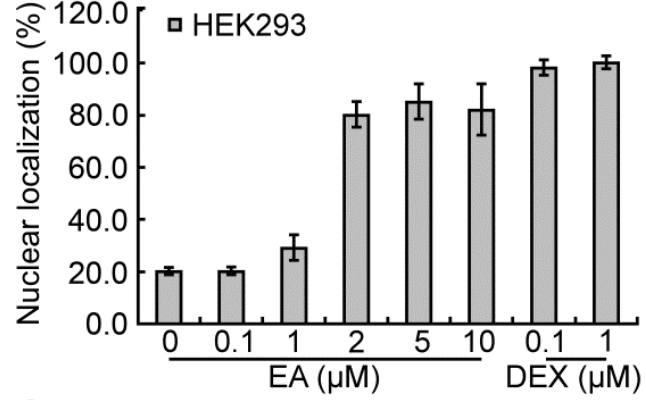

E) $\overbrace{}^{120.0}[$ a HeLa

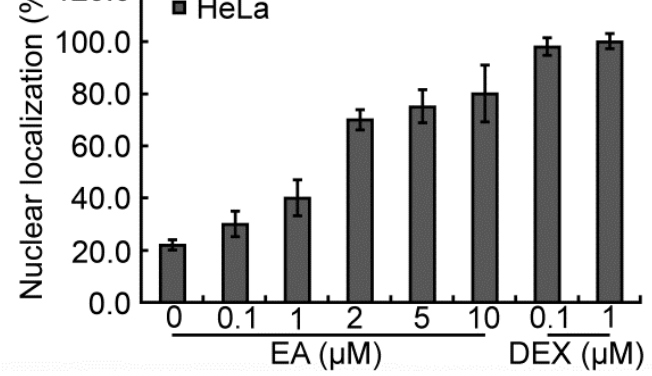

Supplementary Figure 1

$5 \mu \mathrm{M}$ EA-3G

$0.1 \mu \mathrm{M} \mathrm{DEX}$

$2 \mu \mathrm{M}$ EA

$5 \mu \mathrm{M} \mathrm{EA-3G}$
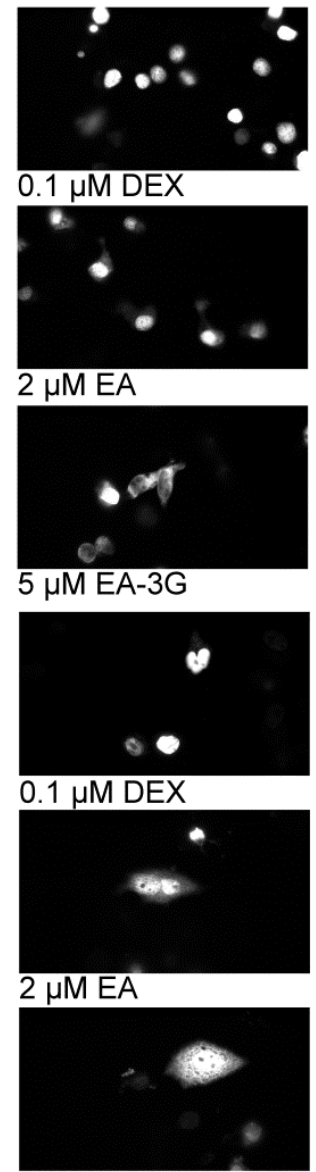

\section{0}

D) $\stackrel{\circ}{\circ} 120.0[$ 口 HEK293

$5 \mu \mathrm{M}$ EA

$5 \mu \mathrm{M}$ EA

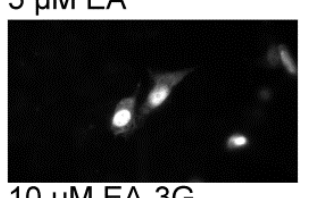

$10 \mu \mathrm{M}$ EA-3G

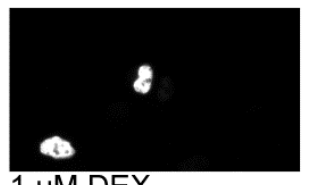

$1 \mu \mathrm{M}$ DEX
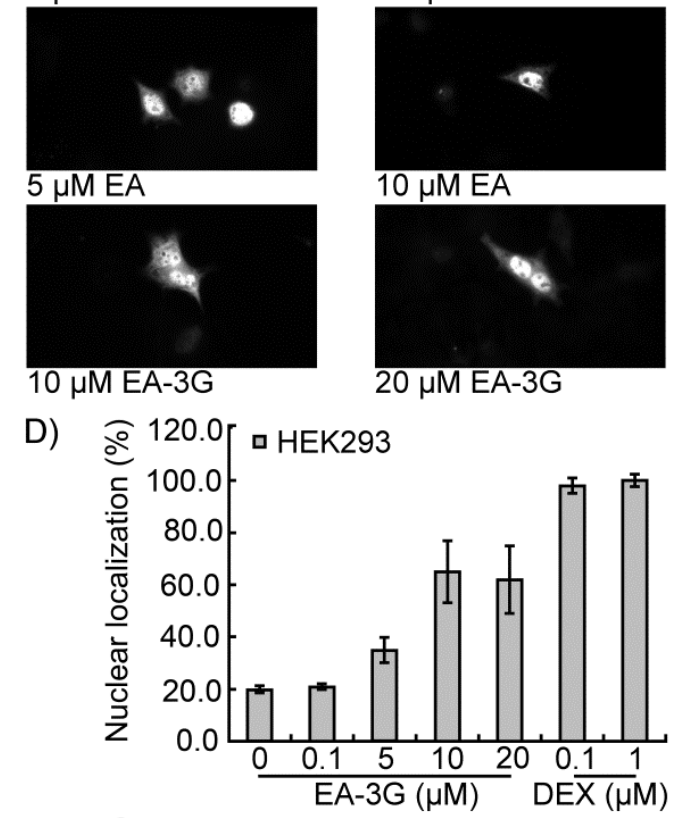

F) $\overbrace{}^{\circ} 120.0[\square \mathrm{HeLa}$

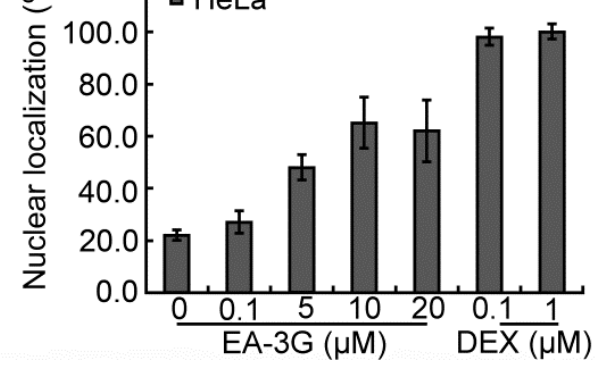

